УдК $82($ о9г)

ББК $83.3(0) 4$
К АНАЛИЗУ ОБРАЗА ХАЛИФА АЛИ

В МАЛАЙСКОЙ НАРРАТИВНОЙ

ТРАДИЦИИ

(C) 2018 г. Л.В. Горяева

Институт востоковедения

Российской академии наук, Москва, Россия

Дата поступления статьи: го ноября 2017 г.

Дата публикации: 25 марта 2018 г.

DOI: I0.22455/2500-4247-20I8-3-I-58-67

Аннотация: С приходом ислама в регионе островной Юго-Восточной Азии начинают распространяться сюжеты, посвященные Пророку Мухаммаду и его ближайшим сподвижникам. Важнейшее место в их ряду занимают малайские повести о ранних войнах ислама, героем которых выступает четвертый из «праведных» халифов - Али ибн Абу Талиб («Повесть о радже Хандаке», «Повесть о радже Лахаде», «Повесть об Абу Бакре»). В этих повестях Али представлен великим воином и одновременно святым, самым просвещенным из числа сподвижников Мухаммада. Подобно пророку Сулейману, Али обладает властью над джиннами и животными, наделен сверхъестественными способностями. При ближайшем рассмотрении становится ясно, что в малайских повестях и образ Али, и истории о ранних войнах ислама в целом тесно переплетены с местными преданиями и архаическими верованиями, согласно которым благополучие человека зависит от его отношений с обитающими в мире духами, а также горами, холмами и лесами. Несмотря на свои ближневосточные корни, малайские повести этого цикла обнаруживают множество черт сходства с домусульманской словесностью и театральной традицией островной Юго-Восточной Азии. Трансформация и адаптация образа Али малайской традицией связана по преимуществу с переходом этого персонажа в сферу устного предания благодаря распространенной практике чтения вслух. Очевидно, что по мере своего продвижения на восток сюжеты об Али и других персонажах священной мусульманской истории прошли сложный и долгий путь не только в географическом, но и в жанровом плане. Этот процесс сопровождался непрерывным взаимодействием устной и письменной традиций, постепенно стиравшим границу между легендой и историей.

Ключевые слова: Али, Мухаммад, ранние войны ислама, малайская литература, устная традиция.

Информация об авторе: Любовь Витальевна Горяева - кандидат филологических наук, ведущий научный сотрудник, Институт востоковедения Российской академии наук, ул. Рождественка, д.І2, Іо703г г. Москва, Россия.

E-mail: goriaeva@mail.ru 


\section{ON THE IMAGE OF CALIF ALI IN MALAY NARRATIVE TRADITION}

This is an open access article distributed under the Creative Commons Attribution 4.0 International (CC BY 4.0)
(C) 20I8. L.V. Goriaeva Institute of Oriental Studies, Russian Academy of Sciences, Moscow, Russia Received: November 10, 2017

Date of publication: March 25, 2018

Abstract: With the advent of Islam in the region of maritime Southeast Asia, stories about Prophet Muhammad and his closest companions began to spread there. The most important ones among them are Malay stories about early Islam wars, featuring the fourth of the "righteous" caliphs - Ali ibn Abu Talib - as their character ("The Tale of Rajah Handak”, “The Tale of Raja Lahad”, "The Tale of Abu Bakr"). In these stories, Ali is represented as both a great warrior and a saint, the most enlightened of Muhammad's companions. Like the prophet Sulaiman, Ali has power over jinnies and animals and is endowed with supernatural capacities. At close examination, it becomes clear that in the Malay stories, the image of Ali and the stories about the early Islam wars are intertwined with local legends and archaic beliefs according to which the well-being of a person depends on his or her relations with the spirits inhabiting the world, and with mountains, hills and forests. Their Middle Eastern roots notwithstanding, Malay stories of this series reveal many similarities to the pre-Islamic literature and to the theatrical tradition of maritime Southeast Asia. Transformation and adaptation of the image of Ali by Malay tradition are associated primarily with the transition of this character into the realm of oral tradition due to the widespread practice of reading books aloud. Obviously, as we move eastwards, stories about Ali and other characters of the sacred Muslim history undergo serious generic changes. This process is accompanied by continuous interaction of oral and written traditions, gradually merging the boundary between legend and history.

Keywords: Ali, Muhammad, early Islam wars, Malay literature, oral tradition.

Information about the author: Liubov V. Goriaeva, $\mathrm{PhD}$ in Philology, Leading Research Fellow, Institute of Oriental Studies, Russian Academy of Sciences, Rozhdestvenka I2, I0703I Moscow, Russia.

E-mail: goriaeva@mail.ru 
Возникновение малайской письменной традиции в ее дошедших до нас образцах принято связывать с эпохой, когда ислам становится господствующей религией островной Юго-Восточной Азии - сначала в княжестве Самудра-Пасей на северо-востоке Суматры (XIII в.), затем в Малакке, Аче (XV в.) и Джохоре-Риау (XVI в.). Сочинения вероучительного характера, предания и легенды исламского происхождения начали распространяться на северо-западе региона благодаря присутствию купцов из Ближнего и Среднего Востока, которые подолгу задерживались в тех краях в ожидании попутного муссона. Вместе с ними там появлялись и проповедники ислама, которые рассказывали жителям прибрежных портовых городов о жизни Пророка и его деяниях.

Рукописи, содержащие изложение мусульманской доктрины и написанные по-арабски с подстрочным переводом на малайский на основе адаптированной для этого языка арабской графики - джави, получают хождение в регионе, по меньшей мере, с конца XVI в. [4, 4 sqq]. Вместе с исламом в малайский мир приходят не только сочинения богословского характера, но и множество ближневосточных преданий, связанных с историей возникновения мусульманской религии, повестей о пророках древности, о Мухаммаде, его сотоварищах, исламских героях и подвижниках благочестия.

Отдельную группу текстов представляют собой малайские повести о войнах Пророка. Генетически они восходят к арабским повествованиям о военных походах Мухаммада, тесно связанным с устной традицией доисламских эпических сказаний о межплеменных войнах (айам ал-араб) и 
впоследствии оформлявшимся в биографические своды (сира). Наиболее раннее произведение этого жанра, где завоевательным походам Мухаммада посвящен специальный раздел, принадлежало перу арабского историка Ибн Исхака (704-767/8). Одновременно в арабской традиции продолжали существовать и передаваться от сказителя к сказителю устные предания о военных подвигах Пророка и его сторонников [5, p. 547-548].

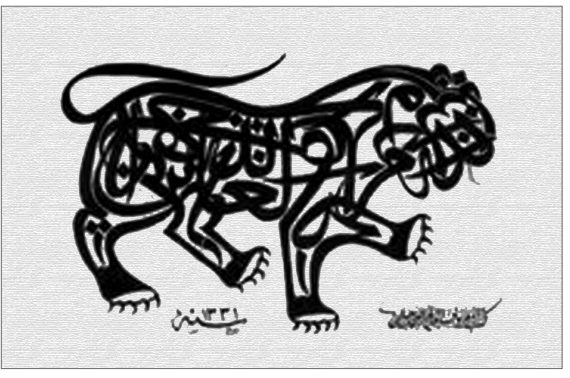

Каллиграфическая композиция на ткани, сложенная из слов: «Именем льва Аллаха, лика Аллаха, Али-победителя». Турция, I33I г.X. (I9I2-I9I3)

Calligraphic composition on the fabric composed of the words: «In the name of Allah's lion, the face of Allah, Ali the Victorer». Turkey I33I (I9I2-I9I3)

Переход преданий жанра сира в другие языки и культуры сопровождался неизбежной утратой их исторической достоверности, все большей и большей отдаленностью от первоисточника. По мере продвижения этих сюжетов на юго-восток Азии сказители-неарабы, передававшие их из уст в уста, перекраивали сюжеты на свой лад, давали свое собственное толкование событиям. Известно, в частности, что многие малайские истории о Мухаммаде восходят к персидским (шиитским) прототипам.

Если в пришедших с Ближнего Востока трактатах религиозного и юридического содержания следовало соблюдать верность букве, то популярный среди малайцев жанр повести (хикайат) допускал более свободное обращение с материалом. В соответствии с существующей практикой, добавки к тексту и правку вносили по своему усмотрению и копиисты. Так с течением времени в малайской литературе сформировался своеобразный жанр «исламского хикайата». В отличие от жанра сира, требовавшего точности, хикайат давал свободу вымыслу, когда исторические факты бессознательно искажались в угоду занимательности повествования. Элементы народных верований и мировосприятия все глубже проникали в малайский исламский хикайат, а исторические персонажи рисовались живыми людьми и наделялись чертами, близкими для малайцев. 
В числе историй о Пророке, созданных безымянными малайскими авторами, особое место занимают повествования о битвах Мухаммада против его врагов. Это, например, «Повесть о Радже Хандаке», «Повесть о радже Лахаде» и другие. Их действие разворачивается в Мекке, Медине и других областях Аравии, какими их представлял себе местный автор.

Названия повестей служат отголоском сражений с участием пророка Мухаммада, имевшим место в 627-630 гг. Заглавие «Повести о Радже Хандаке» отсылает читателя к знаменитой «Битве у рва» 627 г. (от арабского «хандак» - ров), призванной защитить Пророка и его соратников от нападения врагов - мекканцев. Согласно Корану, битвы как таковой не было - Аллах наслал на врага ветер, уничтоживший его палатки и вселивший в него такой ужас, что мекканцы стали отступать без боя (Коран 33: 9-І2). Другое название «Повести о Радже Хандаке» - «Повесть о радже Бадре» - напоминает о битве при Бадре (624), а заглавие «Повести о радже Лахаде» - о битве при Ухуде (627). Здесь топонимы трансформировались в имена собственные, которые носят враги Пророка. Наконец, битва при Хунейне (630) дала имя полю сражения, упоминаемому в той же «Повести о радже Хандаке».

Одним из главных персонажей во всех этих сочинениях выступает Али ибн Абу Талиб, родич и сподвижник Мухаммада. Возможно, причину популярности Али у малайцев следует приписать влиянию персидской, шиитской по духу, традиции (как письменной, так и устной). Образ Али издавна был окружен легендами, о которых еще в Х в. сообщал ал-Масуди: по его словам, в Сиффинской битве Али собственноручно убил 523 ратника, вражеских всадников он рассекал своим мечом надвое так, что их торсы падали на землю, а нижняя часть туловища оставалась в седле [5, p. 3I-32]. Образ Али как воина ислама стал ключевым и в малайских хикайатах.

Выступая как правая рука Пророка в борьбе против врагов истинной веры, он неизменно одерживает над ними верх. Порой Али приписываются победы в битвах, в которых он и не участвовал: например, в «Повести об Абу Бакре» это битва при Кадисии против Сасанидов во время арабского завоевания Ирана (636) - сюжет, окончательно утративший историческую достоверность под пером малайского автора.

Главная ипостась Али - одинокий воин и одновременно святой, обладающий рядом общих черт с пророком Сулейманом: как и тот, Али имеет власть над джиннами, животными и даже неодушевленными предметами. 
Подобно другим классическим героям эпоса, Али наделен сверхъестественными возможностями, является обладателем коня, способного летать по воздуху, и волшебного меча. Вот как описывается Али в «Повести о радже Хандаке»:

Сев на своего скакуна по имени Дулдул Джабарут, Али заставил его взмыть в воздух и испустил троекратный воинский клич. Его действия сотрясали небосвод, который, казалось, вот-вот обрушится на землю и разобьет ее в мелкие куски. Когда Али вновь испустил троекратный клич, три тысячи неверных тотчас же пали мертвыми. Затем он ринулся на врага. Едва он выхватил свой меч Зу-л Факар ${ }^{\text {, }}$ как тот сам собой вытянулся в длину, насколько хватало взора. Тогда Али принялся рубить неприятеля и справа, и слева, и спереди, и сзади от себя, и многие были убиты [8, p. 86].

Прежде чем вступить в сражение, Али обычно призывал противников принять ислам, но, когда они отвечали отказом и вызывали его на битву, Али не оставлял в живых ни одного. В шиитской традиции ему было присвоено прозвище «Лев Аллаха», тогда как в малайских хикайатах непривычное для Юго-Восточной Азии понятие «лев» было заменено на «тигр» - «Тигр Аллаха» [7, p. І05]. Когда в бою Али чувствовал, что теряет силы, он обращался к Всевышнему с просьбой: «О, Аллах, даруй мне нубуат (пророчество)», и получал искомое пророчество, т. е. заверение, что все для него завершится благополучно [8, p. 69-70]. Во время боя Аллах не однажды посылает на подмогу Али свое небесное воинство.

В этих сочинениях Али обычно предстает как наиболее просвещенный из сподвижников Пророка, причем его знания переданы ему самим Мухаммадом. В «Повести о Фатиме» Всевышний освящает союз Али с дочерью Пророка и от имени жениха шлет ей из рая свадебный подарок, сама же церемония происходит «на седьмом небе». Этому же событию посвящен еще один хикайат - «Повесть о бракосочетании Али». Особое положение Али в ряду соратников Пророка подчеркивается и в «Повести о халифе Умаре», где Али находит ответы на все заданные евреями вопросы, чего сам Умар сделать не мог. В «Повести о том, как Пророк наставлял Али» ясно

I $\quad$ Вариант транскрипции - Зульфикар. Меч Мухаммада, перешедший после его смерти к Али и обладающий, по легенде, магической силой и волшебными свойствами [3, с. 79]. 
указывается, что Мухаммад считал своим преемником именно Али и самолично наставлял его в исламской науке [6, p. пі6].

При ближайшем рассмотрении обнаруживается, что и образ Али, и истории о ранних войнах ислама в целом тесно переплетены с местными преданиями и архаическими верованиями, согласно которым благополучие человека зависит от его отношений с обитающими в мире духами, а также горами, холмами и лесами, которые в данном случае выступают союзниками Али. Действие повестей о военных походах Пророка разворачивается в вымышленном антураже Мекки, Медины и соседних с ними областей Аравии. Исходя из собственных представлений об этих незнакомых ему краях, малайский автор упоминает, например, джунгли, через которые якобы пролегает путь героев, или же животных, обитающих в Юго-Восточной Азии, а в Аравии неизвестных: носорогов, а также гиббонов и других крупных обезьян.

Несмотря на свои ближневосточные корни, малайские хикайаты этого цикла обнаруживают множество черт сходства с домусульманской словесностью и театральной традицией островной Юго-Восточной Азии. Это стилистика повествования - его язык, эпитеты и клишированные обороты, эпические повторы при описании типовых сюжетных ситуаций и диалогов.

Во время сражения Всевышний руководит действиями Али через посредство Джабраила, подобно тому, как в малайской версии «Махабхараты» небесные боги сообщают воюющим Пандавам, как им следует поступать, через своего посланца - бегавана Нараду. В «Повести о радже Хандаке» Аллах посылает Джабраила к Пророку с приказом остановить бой под предводительством Али, «пока тот по своему безрассудству не перебил всех неверных до единого, не то в аду никого не останется» [8, p. I36].

Если сравнить Али с братьями-Пандавами, то наибольшее сходство он обнаруживает с могучим и безудержным Бимой (Бхимой) и его сыном Гатоткачей, чье «упоение в бою» небесным богам то и дело приходится сдерживать. В одной из подобных сцен исламские и доисламские, архаические, элементы переплетены особенно причудливо: охваченный амоком Али сражается так яростно, что вызывает тревогу у самого Аллаха - а вдруг невзначай тот ранит своим мечом корову, на которой стоит мир? И Всевышний шлет Джабраила к Али с просьбой, чтобы тот умерил свой пыл, подобно тому, как в «Повести о победоносных Пандавах» боги сыплют с небес цветы, пытаясь 
угомонить разъяренных Гатоткачу и Баладеву, готовых в пылу сражения предать всю землю огню [2, с. I59].

Трансформация и адаптация образа Али малайской традицией связана по преимуществу с переходом этого персонажа в сферу устного предания. «Фольклоризация» исходно письменного материала путем распространенной практики чтения вслух в конце концов привела к тому, что Али, наряду с Джабраилом, Микаилом, Исрафилом, Азраилом и, конечно, Аллахом, стал объектом инвокации в таком архаическом жанре, как шаманское заклинание, дарующее победу над врагом [6, p. 132].

Очевидно, что по мере своего продвижения на восток сюжеты об Али и других персонажах священной мусульманской истории прошли сложный и долгий путь, причем не только в географическом, но и в жанровом плане. Этот процесс сопровождался непрерывным взаимодействием устной и письменной традиций, постепенно стиравшим границу между легендой и историей. И если при переводе богословских или законоведческих трудов малайские книжники строго следовали букве оригинала, то в полуфольклорном хикайате об исламском герое и воине они чувствовали себя более свободно. Об этом свидетельствуют, в частности, строки, которыми завершается «Повесть о радже Хандаке»: «Если что-то в ней [повести. - Л.Г.] написано нескладно или пропущено - добавьте сами, а если сказано что-то лишнее сокращайте, ибо писавший сие неумел и бестолков, способностями своими он ниже всех, сотворенных Аллахом в мире сем» [1, с. 37-46].

Популярность образа Али никоим образом не шла вразрез с общесуннитской доминантой малайско-индонезийского ислама. С одной стороны, этот герой олицетворял преданность Пророку и нетерпимость к врагам его веры, а с другой - напоминал привычные для малайцев фигуры театра плоских кожаных кукол, устных сказаний и издавна знакомых персонажей древнеиндийских эпопей: отважных воителей и любимцев богов. В этом в полной мере проявился «инклюзивный» характер культуры малайского мира, сохранившийся вплоть до наших дней. 


\section{Список литературы}

I Горяева Л.В. Две рукописи «Повести о раджах Пасея» (к истории текста) // Письменные памятники Востока. 2015. № I (22). С. 37-46.

2 Памятники малайской книжности XV-XVIII вв. Повесть о победоносных Пандавах. Бухари ал-Джаухари «Корона царей» / перевод с малайского, исследования, комментарии, приложения и указатели Л.В. Горяевой. М: Вост. лит., 20II. 646 с.

3 Пиотровский М.Б. Зу-л-Факар // Ислам. Энциклопедический словарь. М.: Наука, I99I. C. 79.

$4 \quad$ Syed Muhammad Naquib al-Attas. The Oldest known Malay manuscript: A I $6^{\text {th }}$ century Malay translation on the 'Aqaid of al-Nasafi. Kuala Lumpur, I988. I56 p.

5 Gibb H.A.R, Kramers, J.H. Shorter Encyclopaedia of Islam. Leiden; NY; Köln: E.J. Brill, I995. 67I p.

6 Ismail Hamid. The Malay Islāmic Hikāyat. Kuala Lumpur: Universiti Kebangsaan Malaysia, 1983. 228 p.

$7 \quad$ Wieringa E. Does Traditional Islamic Malav Literature Contain Shi'itic Elements? 'Ali and Fatimah in Malay Hikayat Literature // Studia Islamika. I996. Vol. 3. № 4. P. 93-III.

8 Wijaya E. (ed.) Hikayat Raja Handak Koleksi van de Wall. Perbandingan Alur Naskah W 88 dan W 9I. Fakultas Ilmu Pengetahuan Budaya Universitas, Indonesia. 2008. URL: http://lib.ui.ac.id/file?file=digital/20I60278-RBorWı9oh-Hikayat\%2oRaja.pdf (дата обращения: Іо.09.20I7). 


\section{References}

I Goriaeva L.V. Dve rukopisi "Povesti o radzhakh Paseia” (k istorii teksta) [Two manuscripts of Hikayat Raja Pasai (on the history of the text)]. Pismennye pamiatniki Vostoka, 20I5, no I (22), pp. 37-46. (In Russ.)

2 Pamiatniki malasko knizhnosti XV-XVIII vv. Povest o pobedonosnykh Pandavakh. Bukhari al-Dzhaukhari "Korona tsare" [Texts of Malay written heritage of the $15^{\text {th }}-18^{\text {th }}$ centuries. The tale of victorious Pandawas. Bukhari al-Jawhari “The Crown of Kings”], translation from Malay, research articles, comments, annexes and indexes by L.V. Goriaeva. Moscow, Vost. lit. Publ., 20II. 646 p. (In Russ.)

3 Piotrovski M.B. Zu-l-Fakar [Zu-l-Fakar]. Islam. Ėtsiklopedicheski slovar [Islam. Encyclopedia]. Moscow, Nauka Publ., I99I, p. 79. (In Russ.)

4 Syed Muhammad Naquib al-Attas. The Oldest known Malay manuscript: A I $6^{\text {th }}$ century Malay translation on the 'Aqaid of al-Nasafi. Kuala Lumpur, I988. I56 p. (In English)

5 Gibb H.A.R, Kramers, J.H. Shorter Encyclopaedia of Islam. Leiden; NY; Köln, E.J. Brill, I995. 67I p. (In English)

6 Ismail Hamid. The Malay Islāmic Hikāyat. Kuala Lumpur, Universiti Kebangsaan Malaysia, I983. 228 p. (In Malay)

7 Wieringa E. Does Traditional Islamic Malav Literature Contain Shi'itic Elements? 'Ali and Fatimah in Malay Hikayat Literature. Studia Islamika, I996, vol. 3, no 4, pp. 93-III. (In English)

8 Wijaya E. (ed.) Hikayat Raja Handak Koleksi van de Wall. Perbandingan Alur Naskah W 88 dan W 9I. Fakultas Ilmu Pengetahuan Budaya Universitas, Indonesia. 2008. Available at: http://lib.ui.ac.id/file?file=digital/20I60278-RBorWigoh-Hikayat\%2O Raja.pdf (Accessed September Io, 20I7). (In Indonesian) 